\title{
RAD51 maintains chromosome integrity and mitochondrial distribution during porcine oocyte maturation in vitro
}

\author{
Zhe-Long JIN ${ }^{1)}$ and Nam-Hyung KIM ${ }^{1)}$ \\ 1) Department of Animal Sciences, Chungbuk National University, Cheongju 361-763, Korea
}

\begin{abstract}
DNA repair protein RAD51 homolog 1 (RAD51) plays a central role in homologous recombination (HR) repair of DNA breaks. HR depends on the formation of a RAD51 recombinase filament that facilitates strand invasion. However, the role of RAD51 during porcine oocyte maturation is unknown. The objective of this study was to investigate the expression and function of RAD51 during porcine oocyte maturation in vitro. RAD51 was mainly localized to the nucleus at the germinal vesicle (GV) stage, and was widely distributed in the cytoplasm between the GV breakdown (GVBD) and metaphase II stage. DNA damage induced by etoposide was accompanied by the formation of RAD51 foci that were colocalized with $\gamma \mathrm{H} 2 \mathrm{AX}$. Inhibition of RAD51 increased DNA damage and induced metaphase I arrest along with spindle defects, chromosomal misalignment, and abnormal spindle assembly checkpoint (SAC) activity. Inhibition of RAD51 also increased ROS levels and led to an abnormal mitochondrial distribution. Our results indicate that RAD51 plays a critical role in maintaining chromosome integrity and mitochondrial activity during porcine oocyte maturation.
\end{abstract}

Key words: DNA damage, Mitochondria, Porcine oocyte, RAD51

(J. Reprod. Dev. 63: 489-496, 2017)

I: n mammals, oocytes in the ovary arrest at the dictyate stage of prophase I, called the germinal vesicle (GV) stage, for a very long period of time, from several months to even decades depending on the species [1]. During this time period, the GV oocytes are at risk of DNA damage. DNA damage in germ cells can have many negative effects on the derived progeny, including low birth weight, abortion, and congenital abnormalities [2]. Of the various forms of damage that are inflicted by mutagens, DNA double-strand breaks (DSBs) are considered the most harmful, because one unrepaired DSB is sufficient to trigger permanent growth arrest and cell death [3-5]. The cellular response to DSBs includes activation of serine-protein kinase ataxia telangiectasia mutated (ATM), serine/threonine-protein kinase ataxia telangiectasia and RAD3 related (ATR), serine/threonine checkpoint kinase 1 (CHK1), and checkpoint kinase 2 (CHK2) following phosphorylation of the histone $\mathrm{H} 2 \mathrm{~A}$ variant $\mathrm{H} 2 \mathrm{AX}(\gamma \mathrm{H} 2 \mathrm{AX})$ at the sites of the DSB and activation of the downstream checkpoint that induces cell cycle delay, cell cycle arrest, DNA repair, or the elimination of genetically unstable cells by apoptosis [6].

Homologous recombination (HR) is a well-known DNA repair pathway for DSBs. After a DSB occurs, the DNA repair protein RAD51 promotes invasion of ssDNA into undamaged homologous dsDNA $[7,8]$. A previous study reported that RAD51 regulates cell cycle progression by preserving the $\mathrm{G} 2 / \mathrm{M}$ transition in mouse embryonic stem cells [9]. RAD51 also helps to maintain genome integrity and

Received: May 31, 2017

Accepted: June 22, 2017

Published online in J-STAGE: July 30, 2017

(C)2017 by the Society for Reproduction and Development

Correspondence: N-H Kim (e-mail: nhkim@chungbuk.ac.kr)

This is an open-access article distributed under the terms of the Creative Commons Attribution Non-Commercial No Derivatives (by-nc-nd) License. (CC-BY-NC-ND 4.0: https://creativecommons.org/licenses/by-nc-nd/4.0/) enables cells to resist apoptosis triggered by DNA damage [10]. In addition, RAD51 facilitates replication fork progression, important for maintaining the structural integrity of the chromosomes and ensuring cell proliferation $[11,12]$.

Microinjection of RAD51 into oocytes from the AKR/J mouse strain deficient in DNA repair not only reduced the extent of DSBs but also suppressed apoptosis, thus strengthening the relationship between RAD51 activation and oocyte resistance to cell death [13]. More recently, RAD51 depletion in mouse oocytes was shown to be accompanied by decreased ATP production and mitochondrial membrane potential, and increased DNA degradation, which is probably due to the activated autophagy under RAD51 deficiency in oocytes [14].

To obtain additional insights into the role of RAD51 in mammalian meiosis in the present study, porcine oocytes were selected as a suitable model to investigate the role of RAD51. The maturation time for a porcine oocyte is longer than that for the commonly used mouse model; therefore, providing the opportunity to carry out a more detailed analysis of the cell cycle [15]. The specific RAD51 inhibitor B02 was used in the current study, a cell-permeable pyridinylvinyl-quinazolinone compound that is directly interacts with and controls the activity of RAD51, disrupting its binding to DNA and formation of nucleoprotein filaments. [16, 17]. The objective of this study was to investigate the expression and function of RAD51 during porcine oocyte maturation. DNA damage induced RAD51 foci that were found colocalized with histone $\gamma \mathrm{H} 2 \mathrm{AX}$. Meanwhile, inhibition of RAD51 induced metaphase I (MI) arrest in response to spindle defects, chromosomal misalignment, and abnormal spindle assembly checkpoint (SAC) activity. Furthermore, inhibition of RAD51 increased DNA damage and reactive oxygen species (ROS) levels, induced abnormal mitochondrial distribution, and decreased mitochondrial potential during porcine oocyte maturation. 


\section{Materials and Methods}

\section{Oocyte collection and culture}

All animal handling and experiments were performed according to a protocol approved by the Animal Research Committee of Chungbuk National University, Korea. All chemicals used in this study were purchased from Sigma-Aldrich, unless otherwise indicated. Porcine ovaries were provided by a local slaughterhouse (Umsung, Cheongju, Korea). Cumulus-oocyte complexes (COCs) were aspirated from the follicles (3-8 $\mathrm{mm}$ in diameter) of porcine ovaries and washed three times with 4-(2-hydroxyethyl)-1-piperazineethanesulfonic acid (HEPES)-buffered Tyrode's medium containing $0.1 \%(\mathrm{w} / \mathrm{v})$ poly(vinyl alcohol) (HEPES-TL-PVA). The collected COCs were incubated with in vitro maturation (IVM) medium for $44 \mathrm{~h}$ at $38.5^{\circ} \mathrm{C}, 5 \% \mathrm{CO}_{2}$. The IVM medium comprised tissue culture medium 199 (Gibco) supplemented with $0.1 \mathrm{~g} / 1$ sodium pyruvate, $0.6 \mathrm{mM}$ L-cysteine, $10 \mathrm{ng} / \mathrm{ml}$ epidermal growth factor, $10 \%$ porcine follicular fluid $(\mathrm{v} / \mathrm{v}), 10 \mathrm{IU} / \mathrm{ml}$ luteinizing hormone (Sigma-Aldrich), and $10 \mathrm{IU} /$ $\mathrm{ml}$ follicle-stimulating hormone (Sigma-Aldrich). The COCs were pipetted in TL-HEPES supplemented with $1 \mathrm{mg} / \mathrm{ml}$ hyaluronidase $(\mathrm{w} / \mathrm{v})$ for $3 \mathrm{~min}$.

\section{Quantitative RT-PCR}

Total RNA was extracted from 30 oocytes at each stage using the Dynabeads mRNA DIRECT kit (Invitrogen Dynal AS, Oslo, Norway), and cDNA was obtained by reverse transcription of the mRNA using a cDNA synthesis kit (Takara) with Oligo(dT)12-18 primers and SuperScript III Reverse Transcriptase (Invitrogen Co, NY, USA). The primers used for real-time PCR (RT-PCR) were 5'-AGG TGG AGG TGA AGG AAA GG-3' (forward) and 5'-TAA AGG AGC TGG GTC TGG TG-3' (reverse). The amplification program was: $95^{\circ} \mathrm{C}$ for 3 min followed by 35 cycles of $95^{\circ} \mathrm{C}$ for $15 \mathrm{sec}, 60^{\circ} \mathrm{C}$ for $30 \mathrm{sec}$, and $72^{\circ} \mathrm{C}$ for $20 \mathrm{sec}$, and a final extension step at $72^{\circ} \mathrm{C}$ for $5 \mathrm{~min}$.

\section{Drug treatment}

The RAD51 inhibitor B02 (SML0364, Sigma-Aldrich) was used as a RAD51-specific inhibitor. To investigate the functional roles of RAD51, B02 (stored at $4^{\circ} \mathrm{C}$ until use) was added to IVM medium to a final concentration of 0 (control), 25, 50, or $100 \mu \mathrm{M}$.

\section{Immunofluorescence analysis}

Oocytes were washed with phosphate-buffered saline (PBS) (P4417, Sigma-Aldrich), fixed with 3.7\% paraformaldehyde (w/v) in PBS containing $0.1 \%$ PVA (PBS-PVA), and permeabilized with $1 \%$ Triton X-100 (v/v) for $30 \mathrm{~min}$ at $37^{\circ} \mathrm{C}$. After incubation in blocking buffer (PBS containing $1 \% \mathrm{BSA}$ ) for $1 \mathrm{~h}$, the samples were incubated overnight with different antibodies in a blocking buffer at $4^{\circ} \mathrm{C}$ and washed three times with PBS containing 1\% BSA. The antibodies used were rabbit anti-RAD51 (sc-8349, 1:100; Santa Cruz), mouse anti- $\gamma \mathrm{H} 2 \mathrm{AX}$ (ab26350, 1:100; Abcam), rabbit anti-ATM (pS1981, 1:100; Cell Signaling Technology), goat anti-CHK1 (pS345, 1:100; Santa Cruz), anti- $\alpha$-tubulin conjugated to FITC (F2168, 1:100; Sigma-Aldrich), and anti-BUB3 (mitotic checkpoint protein BUB3; sc-28258, 1:100; Santa Cruz). Stained RAD51 oocytes were treated with $0.1 \%$ pronase for $30 \mathrm{sec}$ to expand the zona pellucida and then centrifuged for $10 \mathrm{~min}$ for removal of the lipid droplets prior to fixation. The oocytes were washed three times with PBS-PVA, and then labeled with a FITC-conjugated antibody $(1: 100)$ for $1 \mathrm{~h}$ at room temperature. The oocytes were counterstained with $5 \mu \mathrm{g} / \mathrm{ml}$ Hoechst 33342 (Sigma Life Science) for $15 \mathrm{~min}$, mounted on a glass slide, and examined using an LSM 710 META confocal laser-scanning microscope (Zeiss, Jena, Germany).

\section{Fluorescence intensity analysis}

Image J software (v.1.47) was used to define a region of interest (ROI) and the average fluorescence intensity per unit area within the ROI was determined. Independent measurements using identically sized ROIs were obtained for the nucleus or cytoplasm. The average values of all measurements were used to obtain the final average intensities and control and treated oocyte values were compared.

\section{Chromosome spreads}

MI oocytes were incubated in acidic Tyrode's solution (Sigma) for $1 \mathrm{~min}$. After removing the zona pellucida, the oocytes were recovered in IVM medium and fixed with $1 \%$ paraformaldehyde in distilled $\mathrm{H}_{2} \mathrm{O}$ (pH 9.2) containing $0.15 \%$ Triton $\mathrm{X}-100$ and $3 \mathrm{mM}$ dithiothreitol. The glass slides were dried slowly in a humid chamber for several hours. After drying, the slides were blocked with $1 \%$ BSA in PBS for $1 \mathrm{~h}$ at room temperature. Next, the oocytes were incubated with a primary antibody overnight at $4^{\circ} \mathrm{C}$ and then with the secondary antibody for 1 $\mathrm{h}$ at room temperature. DNA on the slides was stained with Hoechst 33342 for $15 \mathrm{~min}$, and then the slides were examined with an LSM 710 META confocal laser-scanning microscope (Zeiss). Data were analyzed with ZEN 2010LSM software (Zeiss) and Image J.

\section{Measurement of MII oocyte ROS levels}

To measure ROS levels, oocytes were incubated with $10 \mu \mathrm{M}$ 2',7'-dichlorodihydrofluorescein diacetate (H2DCFDA) for $15 \mathrm{~min}$ (green fluorescence, UV filter, $100 \mathrm{~nm}$ ). The same procedures were followed for all groups of oocytes, including incubation, rinsing, mounting, and imaging. Image $\mathbf{J}$ software was used to analyze fluorescence intensity.

\section{Staining of mitochondria}

To evaluate the distribution of mitochondria, MII oocytes were incubated in IVC medium supplemented with $0.5 \mu \mathrm{M}$ MitoTracker Red CMXRos dye (Molecular Probes, Eugene, OR) for $30 \mathrm{~min}$ at $38.5^{\circ} \mathrm{C}$, washed three times with PBS-PVA, and counterstained with Hoechst 33342 for 15 min.

\section{Membrane potential assay}

To measure the mitochondrial membrane potential, MII oocytes were washed three times with PBS-PVA and incubated in culture

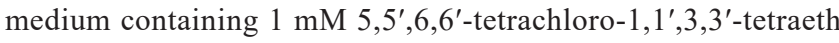
ylimidacarbocyanineiodide (JC-1; Invitrogen, Grand Island, NY, USA) for $30 \mathrm{~min}$ at $37^{\circ} \mathrm{C}, 5 \% \mathrm{CO}_{2}$. The membrane potential was calculated as the ratio of red florescence (activated mitochondria [J-aggregates]) to green fluorescence (less-activated mitochondria [J-monomers]). Fluorescence was visualized with an epifluorescence microscope (Nikon, Tokyo, Japan). The fluorescence intensity of the 
B

A

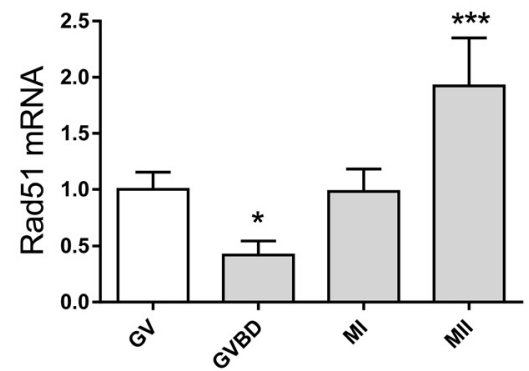

Rad51

GAPDH

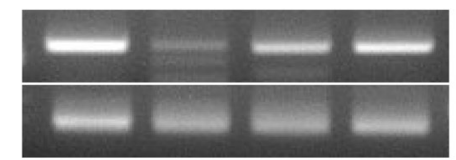

GV

DNA
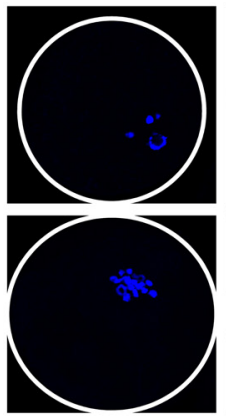

MI

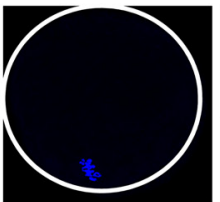

MII

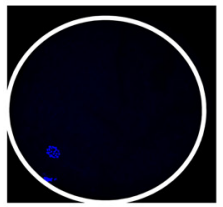

Negative

Control
Rad51
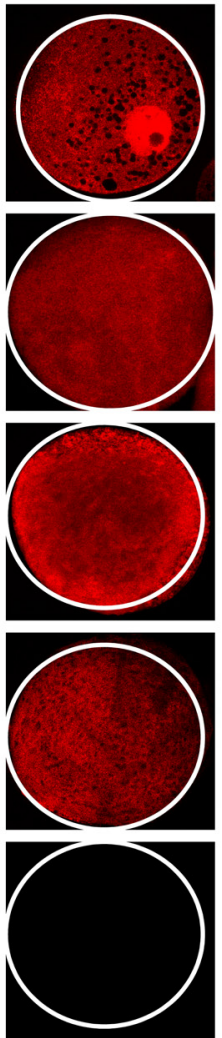

Merge
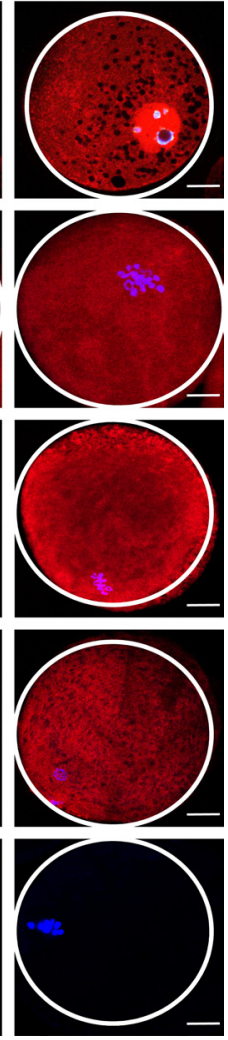

Fig. 1. Expression and localization of RAD51 during porcine oocyte meiotic maturation. (A) Analysis of RAD51 mRNA levels during porcine oocyte meiosis by RT-qPCR. The mRNA levels of RAD51 at the GV, GVBD, MI, and MII stages were $\pm 100, \pm 42, \pm 98.27$, and $\pm 192.33 \%$, respectively. The normalized expression of RAD51 was quantified and is reported as the mean \pm SEM from three independent experiments. ${ }^{*} \mathrm{P}<0.05$. ${ }^{* * *} \mathrm{P}<0.001$. (B) Immunostaining of RAD51 during porcine oocyte meiotic maturation. Hoechst33342 was used for DNA counterstaining. Oocytes were collected at $0,24,30$, and $44 \mathrm{~h}$ of incubation (corresponding to the GV, GVBD, meiosis I, and meiosis II stages, respectively). Red, RAD51; blue, DNA. Scale bar $=20 \mu \mathrm{m}$

control group was arbitrarily set to 1 and the relative fluorescence intensities of the treatment groups were determined. Three separate experiments were performed, with 15-20 oocytes per experiment.

\section{Statistical analyses}

Each experiment was performed at least three times. Statistical analyses were performed with the SPSS software package (Version 11.5; SPSS). The data were expressed as the mean \pm SEM, and analysis of variance (ANOVA) was used to analyze the data. P values less than 0.05 were considered statistically significant.

\section{Results}

\section{Expression and subcellular localization of RAD51 during} meiotic maturation

To investigate the function of RAD51 during oocyte meiosis, RAD51 mRNA levels and the subcellular localization of RAD51 protein were examined. RT-PCR showed that RAD51 mRNA levels were reduced at the GV breakdown (GVBD) stage and increased at the MII stage (Fig. 1A). To assess RAD51 localization, oocytes were cultured for $0,24,30$, and $44 \mathrm{~h}$, which corresponds to the lengths of time required to reach the GV, GVBD, MI, and MII stages respectively. Immunostaining analysis revealed that RAD51 was mainly localized to the nucleus at the GV stage and widely distributed in the cytoplasm beginning at the GVBD stage (Fig. 1B).

\section{Inhibition of RAD51 affects porcine oocyte maturation}

To determine the function of RAD51 during porcine oocyte maturation, oocytes were treated with $0,25,50$, or $100 \mu \mathrm{M}$ B02 (a RAD51 inhibitor) and the rate of oocyte maturation was evaluated. The results showed that RAD51 inhibition did not affect the GVBD rate. After $24 \mathrm{~h} \mathrm{~B} 02$ treatment, the GVBD rates of oocytes treated with $0,25,50$, and $100 \mu \mathrm{M}$ B02 were $91.22,85.75,89.30$, and $83.63 \%$ respectively (Fig. 2A). Unlike the uniform progression to GVBD, porcine oocytes exposed to B02 for $48 \mathrm{~h}$ showed a dose-dependent decrease in polar bodies: $87.94 \%$ of control oocytes developed to the MII stage, whereas only $75.99,58.72$, and $48.93 \%$ of the oocytes treated with 25,50 , and $100 \mu \mathrm{M} \mathrm{B} 02$ were similarly developed (Fig. 2B). For all subsequent studies, porcine oocytes were treated with $50 \mu \mathrm{M}$ B02. 
A

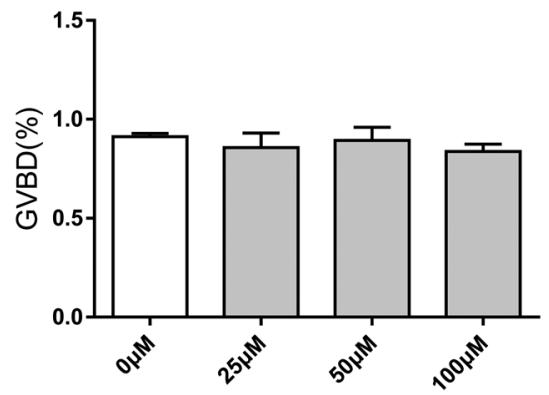

B

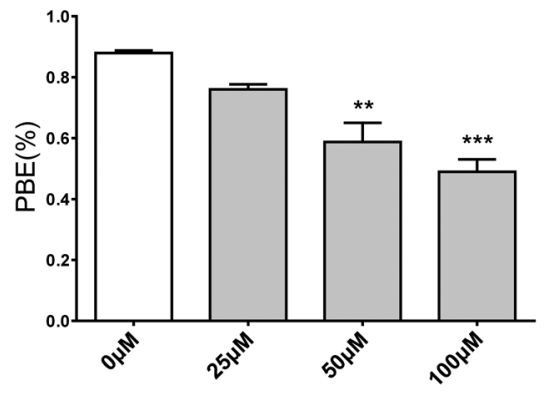

Fig. 2. Inhibition of RAD51 does not affect the rate of GVBD but does decrease the rate of PBE. (A) Effects of RAD51 inhibitor (B02) on the rate of GVBD in porcine oocytes after $24 \mathrm{~h}$ of incubation with $0,25,50$, and $100 \mu \mathrm{M} \mathrm{B} 02$. P $>0.05$, not statistically significant. (B) Effects of the RAD51 inhibitor B02 on the rate of PBE in porcine oocytes after $44 \mathrm{~h}$ of incubation with $0,25,50$, and $100 \mu \mathrm{M} \mathrm{B} 02$. The data were obtained from three independent experiments. ${ }^{* * *} \mathrm{P}<0.001$

A

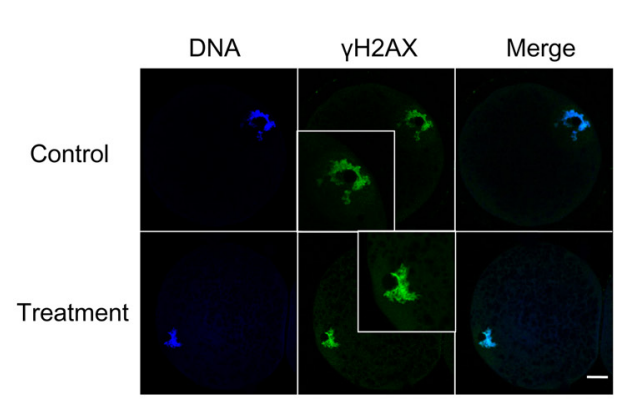

B

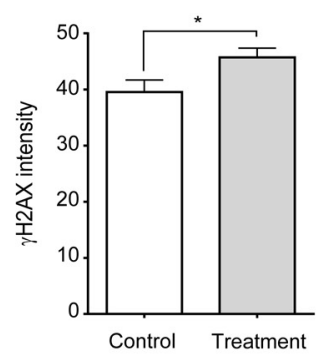

$\mathrm{C}$
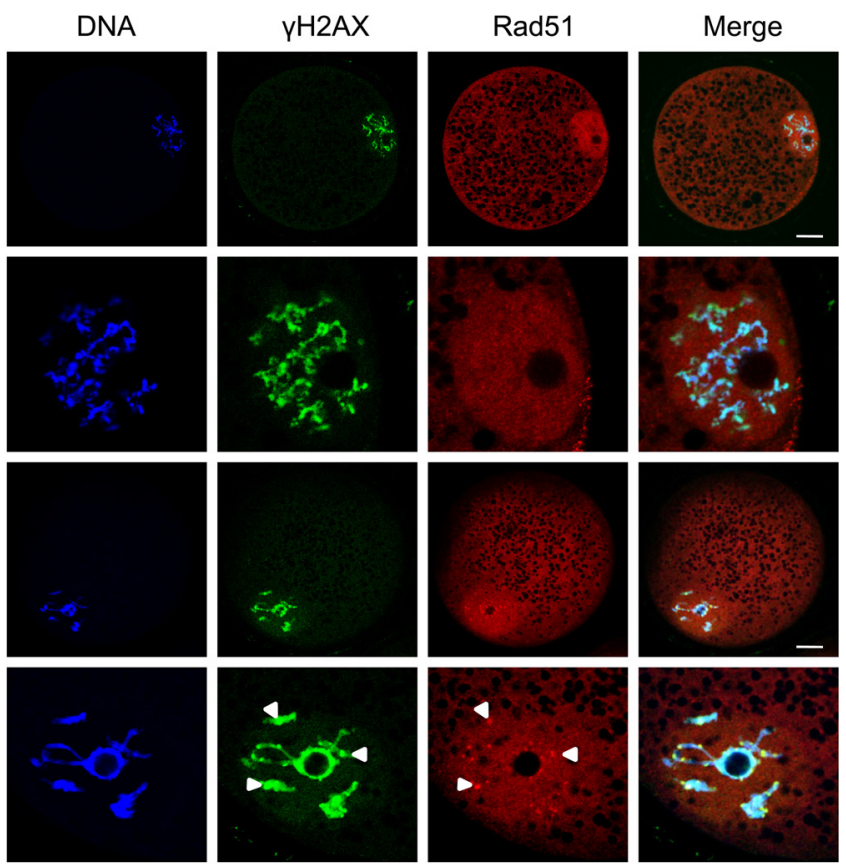

Fig. 3. DNA damage-induced RAD51 foci colocalized with $\gamma \mathrm{H} 2 \mathrm{AX}$ and inhibition of RAD51 increased DNA damage. (A) Oocytes were treated with $\mathrm{B} 02(50 \mu \mathrm{M})$ for $18 \mathrm{~h}$. Green, $\gamma \mathrm{H} 2 \mathrm{AX}$; blue, DNA. Scale bar $=20 \mu \mathrm{m}$. (B) Quantification of $\gamma \mathrm{H} 2 \mathrm{AX}$ intensity after B02 treatment. $* \mathrm{P}<0.05$. (C) Porcine oocytes at GV stage were treated with etoposide $(50 \mu \mathrm{g} / \mathrm{ml})$ for $5 \mathrm{~h}$ to induce DNA damage. H2AX was activated by phosphorylation $(\gamma \mathrm{H} 2 \mathrm{AX})$ at sites of DNA damage and served as a marker of DNA DSBs. RAD51 aggregated as foci in the nucleus and colocalized with $\gamma \mathrm{H} 2 \mathrm{AX}$. Red, RAD51; green, $\gamma \mathrm{H} 2 \mathrm{AX}$; blue, DNA. Scale bar $=20 \mu \mathrm{m}$. The data were obtained from three independent experiments.

Inhibition of RAD51 increased the level of DNA damage in the porcine oocytes

Because RAD51 is required for DNA repair, the influence of the inhibition of RAD51 on DNA damage was assessed by $\gamma \mathrm{H} 2 \mathrm{AX}$ intensity. The results showed that B02 treatment led to an increased accumulation of $\gamma \mathrm{H} 2 \mathrm{AX}$ in comparison with the untreated control group (Fig. 3B and 3C). Next, porcine oocytes were treated with $50 \mu \mathrm{g} / \mathrm{ml}$ etoposide for $5 \mathrm{~h}$ to induce DNA damage. While RAD51 foci did not appear in the control oocytes, RAD51 foci formed in the nucleus and were colocalized with $\gamma \mathrm{H} 2 \mathrm{AX}$ in the treated oocytes (Fig. $3 \mathrm{~A})$, further confirming that RAD51 is required for DNA damage repair in porcine oocytes.

Inhibition of RAD51 does not activate the ATM/CHK1dependent DNA damage checkpoint in porcine oocytes

As RAD51 inhibition increased DNA damage in porcine oocytes, 
A
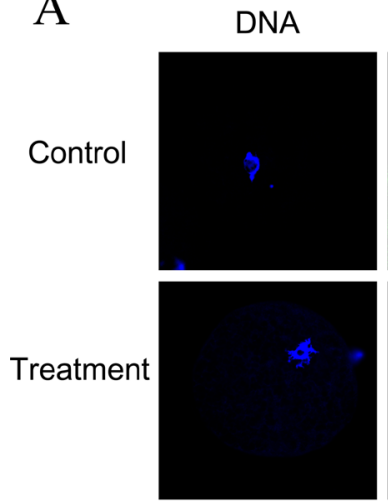

C

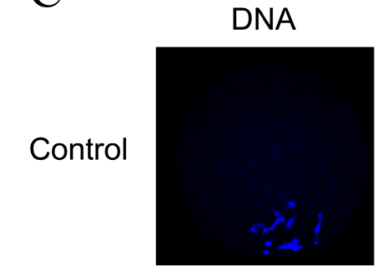

Treatment
CHK1-P
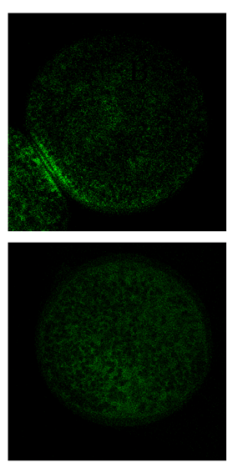

ATM-P
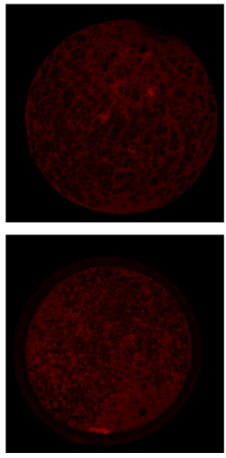

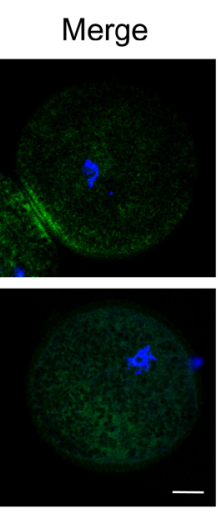

Merge
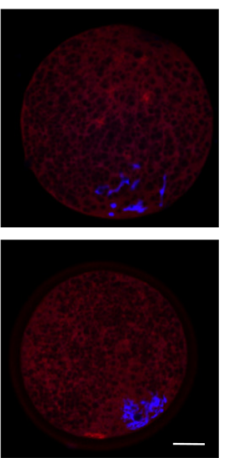

$\mathrm{B}$

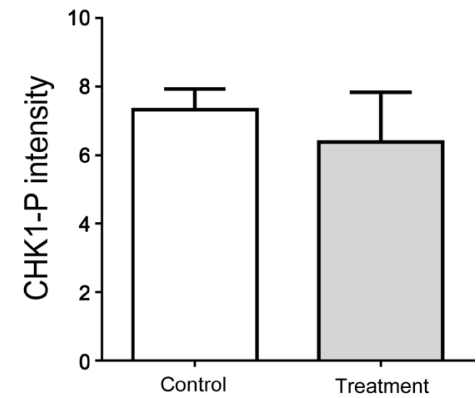

$\mathrm{D}$

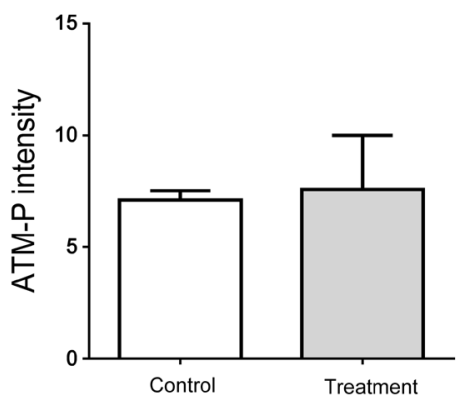

Fig. 4. B02 does not activate the ATM/CHK1-dependent DNA damage checkpoint in porcine oocytes. (A)(C) RAD51 inhibition does not activate the DNA damage checkpoint proteins ATM and CHK1. Porcine GV oocytes were treated with B02 $(50 \mu \mathrm{M})$ for $6 \mathrm{~h}$. After treatment, the phosphorylated CHK1 (CHK1-P) and phospho-ATM (ATM-P) signals did not differ from those in the untreated control. Red, ATM-P; green, CHK1-P; blue, DNA. Scale bar $=20 \mu \mathrm{m}$. (B) Quantification of the ATM-P signal with and without B02 treatment. (D) Quantification of the CHK1-P signal with and without B02 treatment. The data were obtained from three independent experiments. P $>0.05$, not statistically significant.

their involvement in ATM/CHK1 checkpoint activation was explored. Porcine GV oocytes were treated with B02 for $6 \mathrm{~h}$, and the phosphorylated ATM and CHK1 intensity in nuclear was evaluated. ATM was almost inactive in B01-treated oocytes when compared with untreated control oocytes (Fig. 4A and 4B). CHK1, the downstream effector of the ATM-dependent G2/M checkpoint, was also inactive in treated oocytes (Fig. 4C and 4D). Moreover, exposure of the oocytes to a higher concentration of B02 $(100 \mu \mathrm{M})$ did not activate the ATM and CHK1 checkpoint (data not shown).

\section{B02 Inhibition of RAD51 resulted in spindle defects and abnormal SAC activity}

Since treatment with B02 decreased the rate of polar body extrusion (PBE) and increased DNA damage, the effect of B02 on the progression of spindle assembly and chromosome alignment was assessed. Oocytes treated with B02 $(50 \mu \mathrm{M})$ showed disrupted spindle assemblies at the MI and MII stages, while barrel-shaped spindles were observed in control oocytes. Chromosomes were also misaligned in MI and MII oocytes treated with B02, which was not observed in untreated controls (Fig. 5A and 5B).

Because the SAC is known to control PBE- and B02-mediated abnormal spindles [18], SAC activity was explored in the present experiment. To this end, the level of BUB3, a protein involved in $\mathrm{SAC}$ regulation, was assessed after B02 treatment. Porcine oocytes were cultured with B02 $(50 \mu \mathrm{M})$ for $30 \mathrm{~h}(\mathrm{MI}$ stage), and then a chromosome spread was generated and stained for BUB3. Visual inspection showed that the BUB3 signal was weaker in control oocytes than in B02-treated oocytes (Fig. 6A) and quantitation of the staining intensity confirmed this difference (Fig. 6B). The abovementioned results indicate that RAD51 inhibition resulted in spindle defects and abnormal SAC activity.

\section{RAD51 inhibition leads to abnormal mitochondrial distribution and increased intracellular ROS levels}

The mitochondrial distribution pattern in B02-treated MII oocytes was different from that of control MII oocytes (Fig. 7A and 7D). In control oocytes, mitochondria were distributed throughout the ooplasm, whereas in B02-treated MII oocytes, the mitochondria were abnormally distributed and had a lower membrane potential (Fig. 7B and 7E). Next, we determined the effect of RAD51 inhibition on ROS production and observed that the fluorescence intensity of ROS staining increased significantly after treatment with B02 (Fig. 7C and 7F), indicative of an increase in oxidation activity following RAD51 inhibition. 


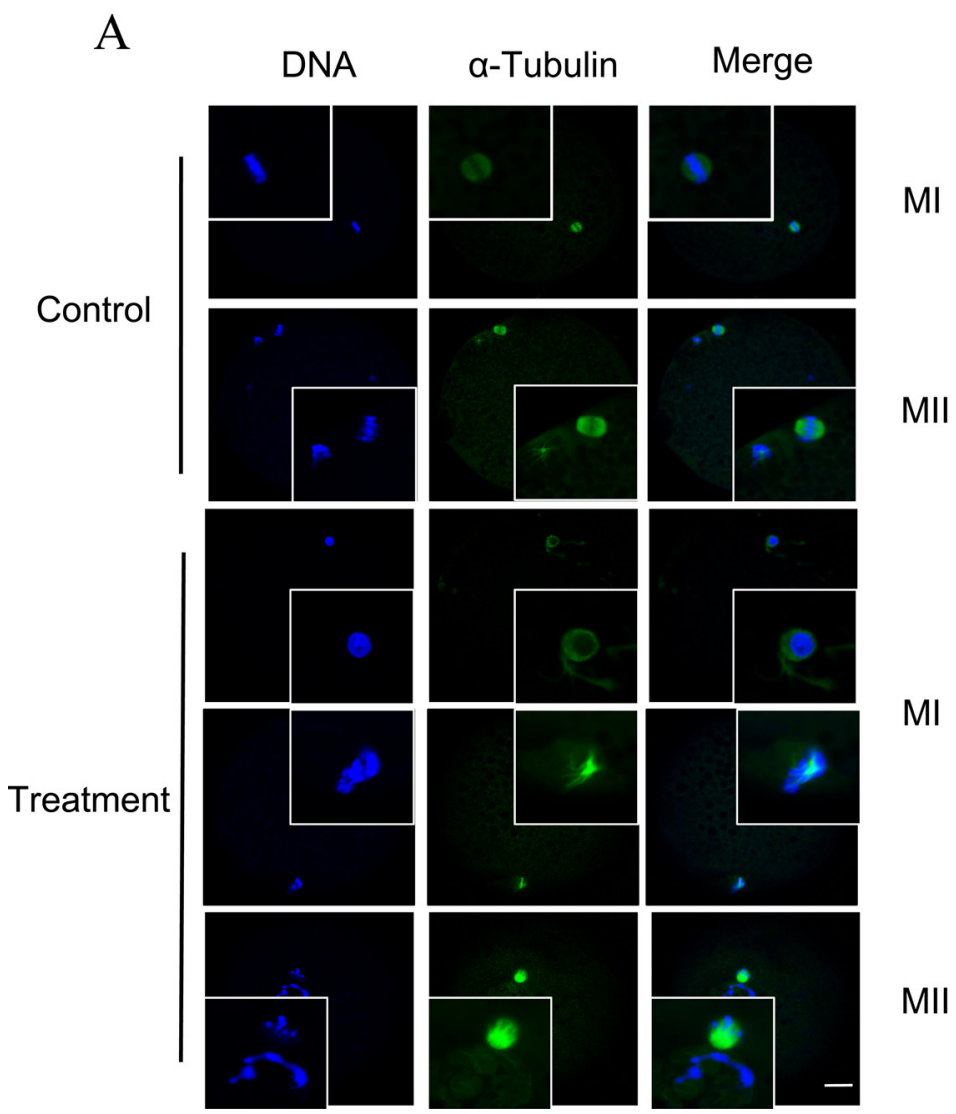

$\mathrm{B}$

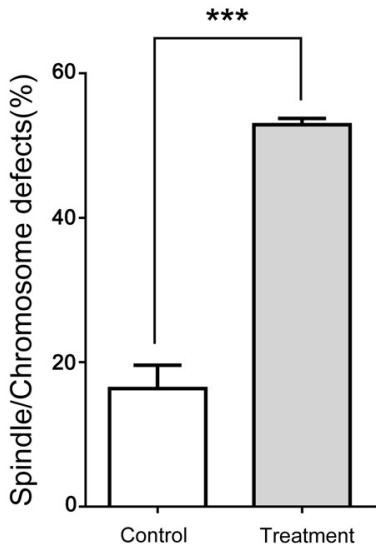

Fig. 5. RAD51 inhibition resulted in spindle defects and chromosomal misalignments. (A) Porcine oocytes were cultured in the presence of B02 (50 $\mu \mathrm{M})$ for $30 \mathrm{~h}$ (MI stage) and $44 \mathrm{~h}$ (MII stage), and then spindle assembly and chromosomal alignment were assessed. Green, $\alpha$-tubulin; blue, DNA. Scale bar $=20 \mu \mathrm{m}$. (B) Quantification of the percentage of B02-treated $(50 \mu \mathrm{M})$ and control (untreated) oocytes with spindle and chromosomal defects. The data were obtained from three independent experiments. ${ }^{* *} \mathrm{P}<0.01$. ${ }^{* * *} \mathrm{P}<0.001$.

A

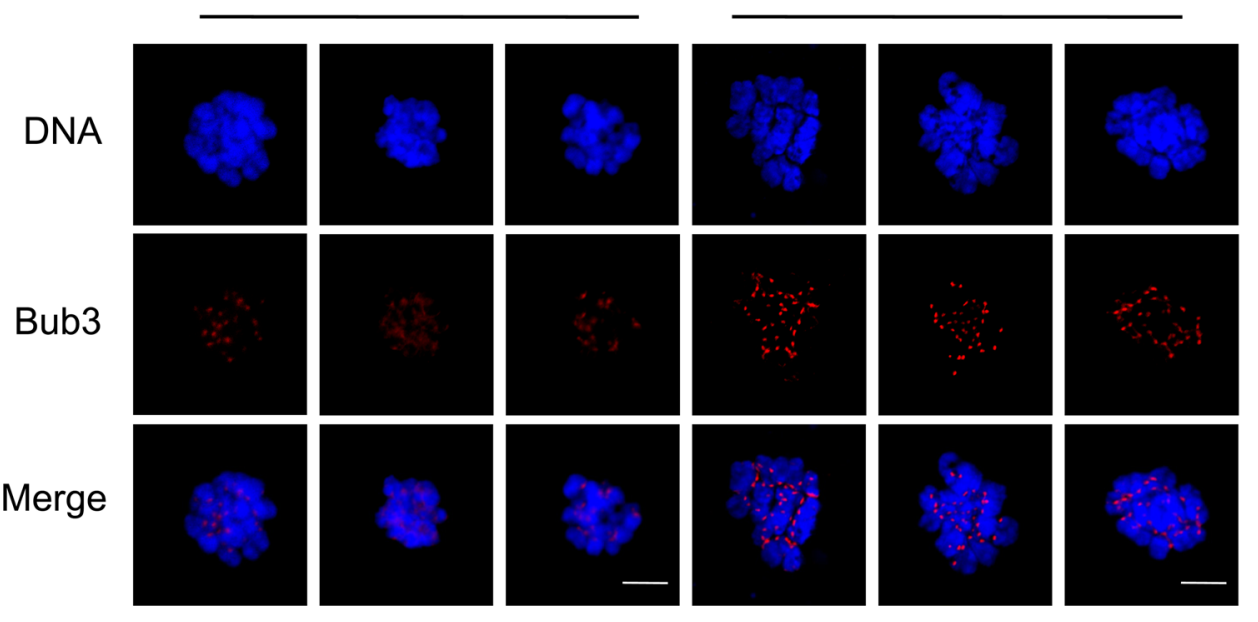

B

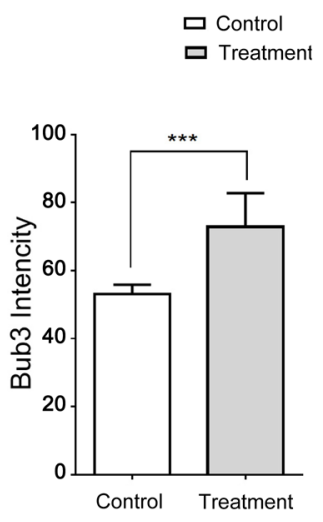

Fig. 6. RAD51 inhibition mediated abnormal SAC activity. (A) Chromosome spread of control and B02-treated (50 $\mu \mathrm{M})$ MI oocytes immunostained for BUB3. RAD51 inhibition increased SAC activity as the BUB3 signal in B02-treated oocytes is stronger than that in the control oocytes. Red, BUB3; blue, DNA. Scale bar $=10 \mu \mathrm{m}$. (B) Quantification of BUB3 intensity in B02-treated and control oocytes. The data were obtained from three independent experiments. $* * * \mathrm{P}<0.001$. 

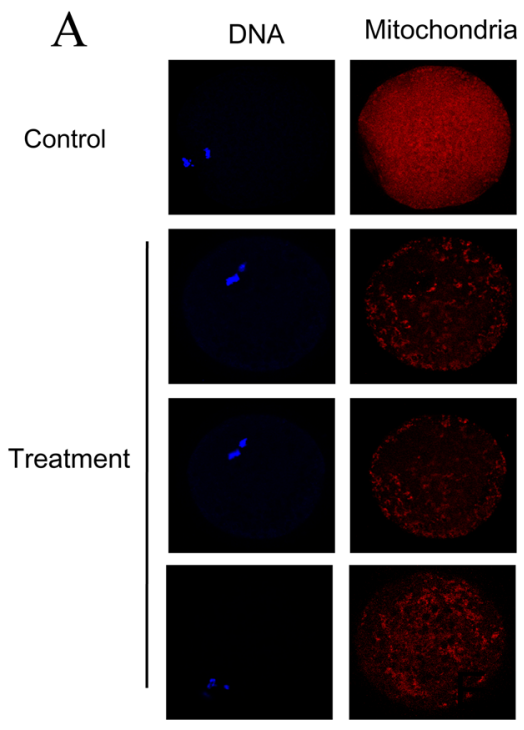

$\mathrm{D}$

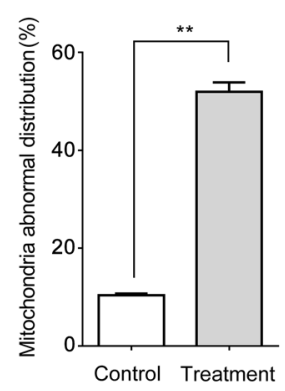

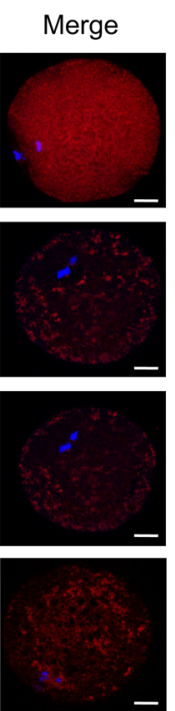

$\mathrm{E}$

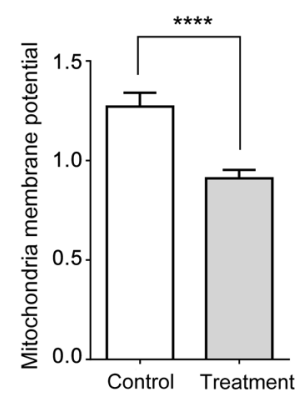

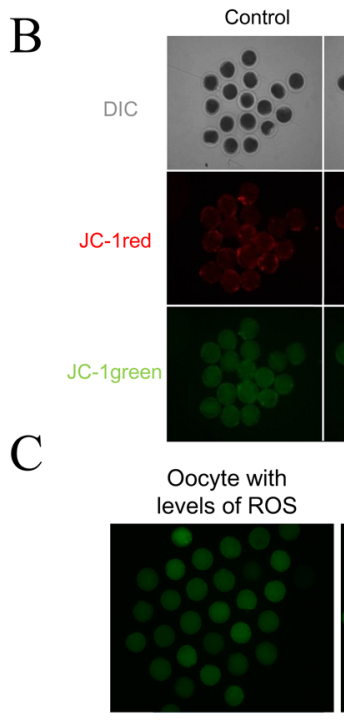

Control

$\mathrm{F}$

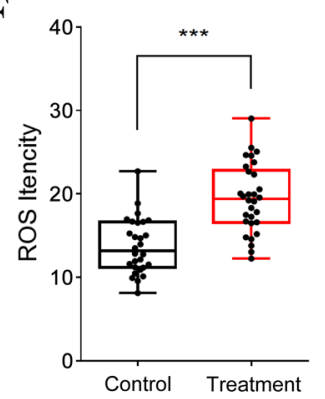

Fig. 7. RAD51 inhibition led to abnormal mitochondrial distribution and increased intracellular ROS levels. (A) Mitochondrial distribution in RAD51 inhibitor-treated and untreated control oocytes as detected by immunostaining. Porcine oocytes were cultured in the presence of B02 (50 $\mu \mathrm{M})$ for 44 $\mathrm{h}$ (MII stage). Red, mitochondria; blue, DNA. Scale bar $=20 \mu \mathrm{m}$. (B) Red fluorescence corresponds to activated mitochondria and green fluorescence corresponds to less-activated mitochondria. Scale bar $=120 \mu \mathrm{m}$. (C) ROS staining in B02-treated $(50 \mu \mathrm{M})$ and untreated (control) MII oocytes. Scale bar $=240 \mu \mathrm{m}$. (D) Percentage of B02-treated $(50 \mu \mathrm{M})$ and untreated (control) oocytes with abnormal mitochondrial distribution. $* * \mathrm{P}<0.01$. (E) Membrane potential was measured as the ratio of red fluorescence to total fluorescence. ${ }^{* * * *} \mathrm{P}<0.0001$. (F) ROS levels in B02-treated and control oocytes were measured as green fluorescence intensity. $* * * \mathrm{P}<0.001$. The data were obtained from three independent experiments.

\section{Discussion}

RAD51 foci spontaneously form during mitosis as cells undergo DNA replication in S phase or in response to DNA damage [19]. Here, a similar distribution pattern of RAD51 was observed in meiotic oocytes. RAD51 was mainly localized to the nuclear region, and a number of distinct nuclear RAD51 foci formed after treatment with the DNA-damaging agent etoposide. DNA damage-induced RAD51 foci also colocalized with $\gamma \mathrm{H} 2 \mathrm{AX}$. The accumulation of the recombination proteins $\mathrm{RAD} 51$ and $\gamma \mathrm{H} 2 \mathrm{AX}$ supports the notion that these foci represent sites where repair reactions are occurring. This further confirms the significance of RAD51 in DNA repair during porcine oocyte maturation. However, it has been reported that upregulation of RAD51 leads to genome instability and the increased resistance of cancer cells to radiation and drug treatment [20]. Therefore, the nuclear availability of RAD51 must be carefully regulated to allow appropriate levels of recombination to occur, both before and after exposure to DNA damage.

In response to DNA damage, oocytes activate the ATM/CHK1dependent DNA damage checkpoint, blocking cell cycle progression to allow time for repair and thereby preventing transmission of damaged or incompletely replicated chromosomes [21]. Previously, in mouse embryonic stem cells, suppression of RAD51 expression caused cells to accumulate at the $\mathrm{G} 2 / \mathrm{M}$ phase and activated the DNA damage checkpoint [9]. Our results demonstrate that inhibition of RAD51 increased DNA damage and inactivated ATM and CHK1 in porcine oocytes, but did not affect GVBD rates. Despite the accumulation of DNA damage, these oocytes underwent GVBD and entered MI. This implies that RAD51 is not required for the G2/M phase transition in porcine oocytes. Compared to blastocysts, oocytes have limited ATM checkpoint activation activity [22]. In addition, it has been suggested that inactivated ATM may result from slight DNA damage and a low abundance of ATM in oocytes [22]. Porcine oocytes do not possess sufficient levels of any active checkpoint proteins, therefore 
low levels of DNA damage fail to effectively activate ATM, while severe DSBs fail to activate CHK1 [1]. The molecular mechanisms regulating the $\mathrm{G} 2 / \mathrm{M}$ transition remain to be elucidated, particularly those underlying the DNA damage responses in porcine oocytes.

In this study, inhibition of RAD51 with B02 disrupted spindle organization and led to abnormal SAC activation in porcine oocytes, where spindle defects led to reduced maturation. Recent studies have implicated the SAC in delaying oocyte progression through meiosis I [18]. The abnormal SAC activity caused by RAD51 inhibition in the present study may have induced DNA damage because DNA damage-induced MI arrest is mediated by the SAC [23]. Furthermore, there is growing evidence for crosstalk between the DNA damage response (DDR) and the SAC. As such, proteins associated with the DDR also have roles in the SAC [24-26].

In the present research, RAD51 inhibition reduced oocyte quality, as indicated by disrupted mitochondrial distribution and ROS accumulation. Mammalian oocyte maturation requires cellular ATP, where oocytes with low ATP levels have poor developmental potential, whereas oocytes with high ATP levels have great potential for further development, embryogenesis, and implantation [27, 28]. Enhanced ATP production is related to mitochondrial aggregation. During oocyte maturation, mitochondria translocate and forma mitochondrial clusters. Moreover, most of the ATP in oocytes is generated by changes in mitochondrial distribution [27]. In mammalian oocytes, mitochondrial localization is microtubule-dependent [28, 29]. Thus, disruption of spindle assembly following RAD51 inhibition is likely related to the abnormal distribution of mitochondria, in agreement with previous results showing that the anatomical association of spindles and mitochondria is linked to meiotic progression in oocytes [28, 30].

In conclusion, inhibition of RAD51 did not affect GVBD, but led to reduced oocyte maturation by disrupting spindle organization and spindle assembly checkpoint activation in porcine oocytes. RAD51 inhibition increased DNA damage, reduced oocyte quality, and as indicated by the disrupted mitochondrial distribution, decreased the mitochondrial membrane potential and induced ROS accumulation.

\section{Acknowledgments}

The work was supported by a grant from the Bio Green 21 Program (grant no. PJ011126) of the Rural Development Administration (RDA), Republic of Korea. This work was supported by the research grant of Chungbuk National University in 2014.

\section{References}

1. Zhang T, Zhang GL, Ma JY, Qi ST, Wang ZB, Wang ZW, Luo YB, Jiang ZZ, Schatten H, Sun QY. Effects of DNA damage and short-term spindle disruption on oocyte meiotic maturation. Histochem Cell Biol 2014; 142: 185-194. [Medline] [CrossRef]

2. Jacquet P. Sensitivity of germ cells and embryos to ionizing radiation. $J$ Biol Regul Homeost Agents 2004; 18: 106-114. [Medline]

3. Wang Z-W, Ma X-S, Ma J-Y, Luo Y-B, Lin F, Wang Z-B, Fan H-Y, Schatten H, Sun Q-Y. Laser microbeam-induced DNA damage inhibits cell division in fertilized eggs and early embryos. Cell Cycle 2013; 12: 3336-3344. [Medline] [CrossRef]

4. Bennett CB, Lewis AL, Baldwin KK, Resnick MA. Lethality induced by a single sitespecific double-strand break in a dispensable yeast plasmid. Proc Natl Acad Sci USA 1993; 90: 5613-5617. [Medline] [CrossRef]

5. Sandell LL, Zakian VA. Loss of a yeast telomere: arrest, recovery, and chromosome loss. Cell 1993; 75: 729-739. [Medline] [CrossRef]
6. Stiff T, ODriscoll M, Rief N, Iwabuchi K, Löbrich M, Jeggo PA. ATM and DNA-PK function redundantly to phosphorylate $\mathrm{H} 2 \mathrm{AX}$ after exposure to ionizing radiation. Cancer Res 2004; 64: 2390-2396. [Medline] [CrossRef]

7. Buisson R, Dion-Côté A-M, Coulombe Y, Launay H, Cai H, Stasiak AZ, Stasiak A, Xia B, Masson J-Y. Cooperation of breast cancer proteins PALB2 and piccolo BRCA2 in stimulating homologous recombination. Nat Struct Mol Biol 2010; 17: 1247-1254. [Medline] [CrossRef]

8. Sugawara N, Wang X, Haber JE. In vivo roles of Rad52, Rad54, and Rad55 proteins in Rad51-mediated recombination. Mol Cell 2003; 12: 209-219. [Medline] [CrossRef]

9. Yoon S-W, Kim D-K, Kim KP, Park K-S. Rad51 regulates cell cycle progression by preserving G2/M transition in mouse embryonic stem cells. Stem Cells Dev 2014; 23: 2700-2711. [Medline] [CrossRef]

10. Richardson C, Stark JM, Ommundsen M, Jasin M. Rad51 overexpression promotes alternative double-strand break repair pathways and genome instability. Oncogene 2004; 23: 546-553. [Medline] [CrossRef]

11. Vispé S, Cazaux C, Lesca C, Defais M. Overexpression of Rad51 protein stimulates homologous recombination and increases resistance of mammalian cells to ionizing radiation. Nucleic Acids Res 1998; 26: 2859-2864. [Medline] [CrossRef]

12. Arnaudeau C, Helleday T, Jenssen D. The RAD51 protein supports homologous recombination by an exchange mechanism in mammalian cells. J Mol Biol 1999; 289 1231-1238. [Medline] [CrossRef]

13. Perez GI, Acton BM, Jurisicova A, Perkins GA, White A, Brown J, Trbovich AM, Kim MR, Fissore R, Xu J, Ahmady A, DEstaing SG, Li H, Kagawa W, Kurumizaka H, Yokoyama S, Okada H, Mak TW, Ellisman MH, Casper RF, Tilly JL. Genetic variance modifies apoptosis susceptibility in mature oocytes via alterations in DNA repair capacity and mitochondrial ultrastructure. Cell Death Differ 2007; 14: 524-533. [Medline] [CrossRef]

14. Kim K-H, Park J-H, Kim E-Y, Ko J-J, Park K-S, Lee K-A. The role of Rad51 in safeguarding mitochondrial activity during the meiotic cell cycle in mammalian oocytes. Sci Rep 2016; 6: 34110. [Medline] [CrossRef]

15. Zhang Y, Duan X, Cao R, Liu H-L, Cui X-S, Kim N-H, Rui R, Sun S-C. Small GTPase RhoA regulates cytoskeleton dynamics during porcine oocyte maturation and early embryo development. Cell Cycle 2014; 13: 3390-3403. [Medline] [CrossRef]

16. Huang F, Motlekar NA, Burgwin CM, Napper AD, Diamond SL, Mazin AV. Identification of specific inhibitors of human RAD51 recombinase using high-throughput screening. ACS Chem Biol 2011; 6: 628-635. [Medline] [CrossRef]

17. Huang F, Mazina OM, Zentner IJ, Cocklin S, Mazin AV. Inhibition of homologous recombination in human cells by targeting RAD51 recombinase. $J$ Med Chem 2012; 55: 3011-3020. [Medline] [CrossRef]

18. Sun S-C, Kim N-H. Spindle assembly checkpoint and its regulators in meiosis. Hum Reprod Update 2012; 18: 60-72. [Medline] [CrossRef]

19. Tarsounas M, Davies AA, West SC. RAD51 localization and activation following DNA damage. Philos Trans R Soc Lond B Biol Sci 2004; 359: 87-93. [Medline] [CrossRef]

20. Klein HL. The consequences of Rad51 overexpression for normal and tumor cells. DNA Repair (Amst) 2008; 7: 686-693. [Medline] [CrossRef]

21. Pandita TK, Lieberman HB, Lim D-S, Dhar S, Zheng W, Taya Y, Kastan MB. Ionizing radiation activates the ATM kinase throughout the cell cycle. Oncogene 2000; 19 : 1386-1391. [Medline] [CrossRef]

22. Marangos P, Carroll J. Oocytes progress beyond prophase in the presence of DNA damage. Curr Biol 2012; 22: 989-994. [Medline] [CrossRef]

23. Lin F, Ma X-S, Wang Z-B, Wang Z-W, Luo Y-B, Huang L, Jiang Z-Z, Hu M-W, Schatten H, Sun Q-Y. Different fates of oocytes with DNA double-strand breaks in vitro and in vivo. Cell Cycle 2014; 13: 2674-2680. [Medline] [CrossRef]

24. Dotiwala F, Harrison JC, Jain S, Sugawara N, Haber JE. Mad2 prolongs DNA damage checkpoint arrest caused by a double-strand break via a centromere-dependent mechanism. Curr Biol 2010; 20: 328-332. [Medline] [CrossRef]

25. Eliezer Y, Argaman L, Kornowski M, Roniger M, Goldberg M. Interplay between the DNA damage proteins MDC1 and ATM in the regulation of the spindle assembly checkpoint. J Biol Chem 2014; 289: 8182-8193. [Medline] [CrossRef]

26. Kim EM, Burke DJ. DNA damage activates the SAC in an ATM/ATR-dependent manner, independently of the kinetochore. PLoS Genet 2008; 4: e1000015. [Medline] [CrossRef]

27. Yu Y, Dumollard R, Rossbach A, Lai FA, Swann K. Redistribution of mitochondria leads to bursts of ATP production during spontaneous mouse oocyte maturation. $J$ Cell Physiol 2010; 224: 672-680. [Medline] [CrossRef]

28. Van Blerkom J, Davis PW, Lee J. ATP content of human oocytes and developmental potential and outcome after in-vitro fertilization and embryo transfer. Hum Reprod 1995; 10: 415-424. [Medline] [CrossRef]

29. Sun QY, Wu GM, Lai L, Park KW, Cabot R, Cheong HT, Day BN, Prather RS, Schatten $\mathbf{H}$. Translocation of active mitochondria during pig oocyte maturation, fertilization and early embryo development in vitro. Reproduction 2001; 122: 155-163. [Medline] [CrossRef]

30. Dalton CM, Carroll J. Biased inheritance of mitochondria during asymmetric cell division in the mouse oocyte. J Cell Sci 2013; 126: 2955-2964. [Medline] [CrossRef] 